\title{
Modeling of a Smart University Social Network for the Development of Soft Skills in a Professional Environment (SUSN)
}

\author{
https://doi.org/10.3991/ijet.v16i04.18817 \\ Hamid Bargach, Mohamed Ghailani, Jaber El Bouhdidi ( $\left.{ }^{凶}\right)$ \\ University of Abdelmalek Essaâdi, Tangier, Marocco, \\ jaber.elbouhdidi@uae.ac.ma
}

\begin{abstract}
With the undeniable impact on the yield, the exploitation of collective skills in companies has become, today, inevitable. Web 2.0 seems to offer powerful tools for the formal and efficient management of these skills. However, this requires a new professional act which is generally lacking. The university is therefore called upon to rethink its training practices by acquiring a smart educational and professional social network capable of developing in the student the profile adapted to the collaborative version of companies 2.0. Describing what exists in this area and proposing a techno-pedagogical contribution relating to the role of University 2.0, these are the two objectives that this research targets.
\end{abstract}

Keywords-Web2.0, individual skills, collective skills, enterprise 2.0, university 2.0 , professionalizing situations

\section{Introduction}

The questioning of scientific advances and their impact on the company makes it possible to make the departure between three eras, namely the industrial era, the digital era and that of co-acting. Backed by New Technologies, collaborative communication is gradually taking hold in today's business and aims to mobilize collective skills wisely in order to maximize productivity and production. The appropriate and efficient exploitation of these skills induces, volensnolens, the rehabilitation of the logic of "reliance" both human and scientific and therefore relational and informational sharing that the use of the Web seems to assure. However, the formal digital connection of people and their practices-achievements is not unanimous and poses, apparently, serious problems which illustrate, among other things, the "infobesity" or information overload, entanglement of public and personal uses of social networks as well as the conflict of territory between interests and departments. This state of affairs legitimizes the intervention of the university, which today is called upon to remedy this dysfunction and to techno-pedagogically address the order of the enterprise 2.0, which seeks to enhance collective action and mutualisation. 
In this sense, we have to underline a paradox. The university which should prepare and contribute to the institutionalization and rigorous management of collective skills in the company is itself short of benchmarks and cannot manage to get rid of the divisions which run through it by dividing up knowledge and untying people. In fact, university teaching practices are centered on the individual skills of the students and are concerned with the knowledge which organizes the different programs. Likewise, teachers act separately and do not take part in joint inter-modular and interdepartmental projects. As for social networks, their use for this purpose remains very limited and somewhat spontaneous [1,2].

It would still be necessary to rethink the role of the university and review its functioning both internally and externally so that the formation of a new 2.0 generation capable of communicating in an interactionist manner and of co-developing projects is feasible and assessable. Many questions therefore arise and require concrete, fruitful and operationalizable answers: what use (s) are we currently making of collective skills in enterprise 2.0? What are its limits? What mission should be assigned, therefore, to today's university? What training and evaluation system should be put in place? How to manage, digitally and functionally, intra and inter-modular, intra and interdepartmental joints? By what educational and organizational means could we link university and business?

Thus, three objectives are assigned to our research work. At first glance, take stock of the function of social networks with regard to the development of collective skills in enterprise. Furthermore, define the theoretical framework and stabilize the reference concepts. Ultimately, proceed with the design of a methodological framework, applicable and generalizable, for training in the digital management of collective skills.

\section{State of the Art: Collective Skills and Enterprise 2.0}

In perfect synergy with the current context and the continuous changes it implies, collaborative work and therefore the dialectic of individual skills is no longer optional, but rather a necessity [3,4,5]. Aware of its capital importance, researchers focused mainly on the concept of collective skills at the end of the 20th century, trying to identify it $[6,7,8,9]$.

\subsection{Collective skills subject or vector}

If French-speaking research is concerned with collective competence as an objective, English-speaking research perceives the concept from a utilitarian point of view by associating it with performance:" The notion of collective competence is therefore clearly developed in the French and Quebec literature, but its dominant paradigm is to understand its nature and its manifestations, more than to grasp the links with performance. Conversely, Anglo-Saxon research studies are more interested in the link between collective functioning and performance. 
Nevertheless, whether it is Anglo-Saxon or French-speaking research, the theoretical basis is common, that of interactionism postulated by Palo Alto and reinvested in a number of fields, in cultural anthropology [10], in language science [11] to limit itself to these two disciplinary fields. Interactionism refers to interactional processes, "a combination of three orders of reality which deserve to be considered jointly: the interpersonal order which refers to the mechanisms of coordination and cooperation in forms of collective action, the socio order -historical, which refers to the institutional and cultural environments in which interactions take place, and finally the semiotic order, by which these mechanisms of coordination and orientation in the social environment are accomplished "[12]. Working in this way, collective skills arouse the interest of theorists but also and above all of companies.

\subsection{Concept more and more appraised by companies}

In today's organizations, collaborative work is essential and imposes these processes. It therefore constitutes a necessary alternative [13] to adapt to continuous changes in the environment. [14] The objective is the development of collective competence, which generates performance-process [15], Hence the crucial importance of the role played by the manager [16], which consists in making people adhere to a common vision and values while tolerating error [17] In addition to these tasks, the managercoach is required to make employees responsible and to give them confidence [18].

Thus, the concept of collective competence has been in the spotlight, and this since the 2000s $[19 ; 20 ; 21 ; 22 ; 23]$. It represents the subject of a number of researches, definitions and practices presenting similarities, differences and points of complementarity. All these investigations underline the problematic character of collective competence, but also the dependence of this on individual competences (functional and integration) and the dialectic which these induce [24];

Researchers are generally interested in three fundamental questions, namely the identification of the concept [25, 26, 27], the articulation between individual skills, collective skills and strategic skills $[28,29,30]$ and the establishment and construction of collective skills. This last question deserves to be detailed as follows.

\subsection{Constituents structuring the collective competence}

The interest in collective competence leads to deep questions about the nature of this competence, its constituents and especially its mode of construction and development. From this point of view, we have to point out that there are four components organizing collective competence (reference), in this case shared language, the common frame of reference, collective memory and subjective commitment.

Shared language, also called "common operational language" [31], designates this lexicon co-developed by the working community and which offers it the possibility of "reading between the lines, saving time in abbreviated utterance, avoiding comments and explanations' [32]. It is, in short, this language which ensures fast and efficient intra-group communication and which cannot be accessed by a member belonging to another group. 
As for the common frame of reference, it is the product of a common work and refers to the information gathered by the group and which form standardized representations in the service of everyone. This frame is also the result of a confrontation, a winwin negotiation; negotiations on the objectives to be achieved, the means to be put in place and the efforts to be made.

Furthermore, collective memory is available in three types of memory [33], namely declarative memory (centered on the appropriation of new knowledge through interaction, thanks to peers), procedural memory (resulting from paralleling the know-how of people when carrying out a common task) and the collective memory of judgment (constructed from all the individual memories of judgment linked to the confrontation of individual interpretations formulated in the face of a complex situation - problem).

Finally, subjective engagement refers to the collaborative practice of problem solving [34], to synergism [35]. The members of the work teams also take initiatives and learn to take collective responsibility for them. Cooperatives, managers and selfemployed, employees have access to performance. It should be noted, by the way, that cooperation, which is the sine qua non condition for building collective skills, is based on a voluntary approach by stakeholders [36], which imposes on managers the need to do Soft Skills the determining parameter in terms of the choice of employees. However, the judicious use of collective competence requires not only humanized and ethically founded management, but also advanced implementation and communication tools.

\subsection{Collective competence and angle of attack adopted}

In the light of the theoretical elements questioned, in particular those which identify collective competence and define its nature (competence as an object and competence in the vectorial role) and the constituents, we have attempted to formulate a synthetic definition aligned with the dichotomous logic of technical and behavioral, and in line with the targeted professionalization. We used this definitional matrix to design our Modeling. Here is the full statement: "Collective competence is considered to be the ability, for a team, to put the technical skills (Hard Skills) of its members, in interaction so as to manage their articulations well in order to resolve problem situations of a professional nature (academic context) or professional nature (entrepreneurial context). This interaction implies the appropriation and proper use of behavioral skills (Soft Skills). The following representation allows us to further concretize our approach. 


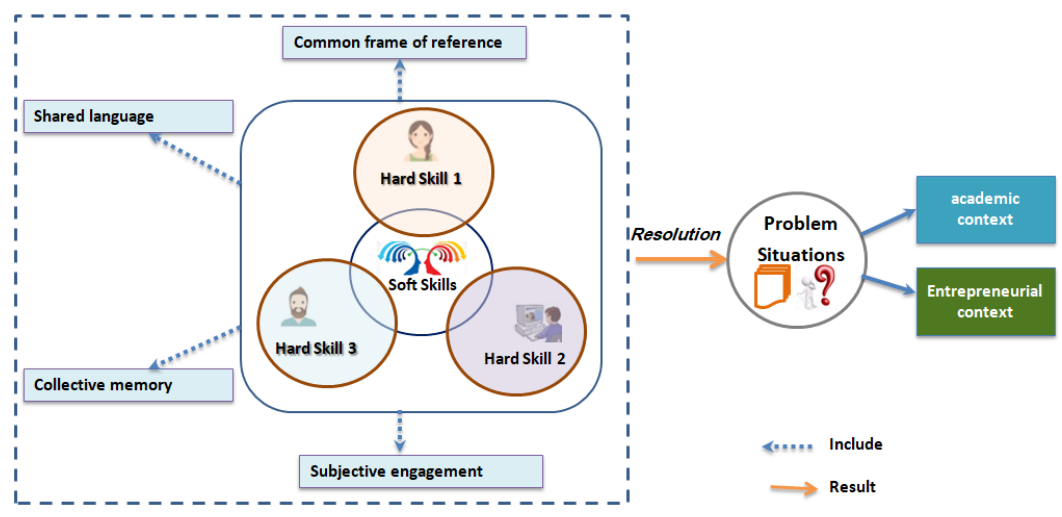

Fig. 1. Collective Competence and its constituents

\subsection{Digital and collective action}

The social web seems to meet this need. But what exactly is the situation in the enterprise 2.0. How do we use the available digital resources? What place does it give to the development of collective skills? What difficulties does the company face at this level?

In fact, a number of internationally renowned companies are using digital technology, specifically the social web, to encourage collaborative work, such as the American company General Electric, which has a squad of micro-messages to teach employees how to use social networks as a way to improve internal cooperation. On the other hand, the Metropolitan Life Insurance Company, or MetLife, has its social network and exploits its potential to facilitate exchange and mutual aid. [37]. Like many others, these companies are practically seeking to ensure the free flow of information and the joint resolution of problems by breaking down the partitions imposed by the verticality of hierarchical operations.

Targeted collective skills inevitably require the use of digital technology. Human resources professionals use, for example, doubly LinkedIn in business, both internally and externally. It is used internally for recruitment as well as for the "development of the employer brand" (concern for efficiency or performance). Externally, that is to say outside the company in terms of job search and "development of its personal brand" ("Establish its personal professional identity"), this is what stands out of a more or less recent study. According to this investigation [38], a survey that targeted a population of 3,249 executives internationally showed that two-thirds use Web 2.0 for work and that the rate of companies using social networks and blogging is increasing.

The increasingly frequent use of digital technology in business has led to terminology at the genesis of new names, namely: networked enterprises and "enterprises 2.0". If the former are interested in the articulation of employee initiatives in order to seek new partners, " 2.0 companies" offer intra and inter-company social platforms. The common objective of the two types of business, despite their divergence, seems to be 
the organization of the work network, an organization with a holistic and humanist vocation promoting collaboration, interaction and professional agility.

Despite its somewhat slow development in French-speaking and English-speaking research and although it is taken advantage of current organizations, aware of the link between the collective functioning of work and output, and therefore between the process and the result obtained, collective competence and the social web favouring it are not systematically exploited and pose a number of problems. First, "Collective work in the company is today paradoxical: valued in the organization by various forms of cooperation and is constrained and weakened in its constitution and sustainability in the face of new forms of employment" [39]. In addition, the emotional aspects seem to be neglected, as is also the case with the balance of power and the hierarchy, which seem threatened and could generate resistance to the change to be implemented. There is another parameter and not the least of which it would be relevant to take into account, in this case the importance of the axiology, of the values that should be revitalized, those of diversity, sharing, negotiation that systemic collective action presupposes.

These shortcomings and requirements lead us to question the role of the university. Aren't university establishments called upon to review their mission and to process this new order in a structured and formal manner? What training and assessments should they introduce? As they stand today, wouldn't universities be required to question how they work? Shouldn't they create internal and external links? How could they manage digitally and functionally inter and intra-modular, intra and interdepartmental articulations, between them and the companies to the needs of which they are invited to adapt?

\section{University 2.0 and Implementation of Collective Skills}

Based on the diagnosed needs of today's organizations and in consideration of the inadequacies of the university training offer, our techno-pedagogical contribution lies in the design of a methodological framework for the implementation of collective skills within the university today. The initiative aims to professionalize training so that it is durably adapted and adaptable to the permanent changes experienced by companies in the era of globalization and collaboration.

According to this logic, we will put, at first glance, the University 1.0 and the different disturbances it knows. Along the way, we will discuss the transition from the "unbinding" 1.0 university to the "connecting" 2.0 university by reviewing the objectives, the basic principles, the conditions of implementation as well as the stakeholders of this project. Ultimately, the outline of the proposed methodological framework will be presented.

\subsection{University 1.0, observation of dysfunctions}

It goes without saying that University 1.0 is the one that makes informal use of digital technology. Teacher-researchers as well as students use the Web either to com- 
municate about their personal lives, or to facilitate their academic work by consulting their letters, archiving their data or carrying out documentary research, among others. The examination of the university space reveals, moreover, a kind of inadequacy of the training provided and the job market, a virtual absence of "reliance" within the modules and between the different modules structuring the program. The "deliance" also concerns the departments which work separately and raise problems of interests and conflict of territory. The university as a whole seems detached from the company and dialogues with it only superficially, especially in the Third World. On the educational level, it should be noted that knowledge prevails over know-how and takes the form of atomized or fragmented information in the absence of a systematic and structured project approach.

The focus on crumbling knowledge is to the expense of technical skills (Hard Skills) but also and above all behavioural skills (Soft Skills) which could, alone, enable the student to acquire other skills. We note, in closing, another dysfunction linked this time to the recruitment of teacher-researchers. In fact, it operates according to technical and non-behavioural skills, the job to be filled and not a global project like companies.

This reality legitimizes the following questions: how could the university promote the culture of collaboration when it is significantly lacking? Reality being what it is, would there be means likely to transcend this paradox? Do the changes in the current company not require a restructuring of the dynamics of university training? How to make the university a place of digital collaborative practices where management and training are thought of in terms of articulation or complexity?

\subsection{From "unbinding" university 1.0 to "connecting" university 2.0}

As indicated, the concern to adapt to a constantly evolving context (multifaceted globalization, competitiveness, results of generalized strategic intelligence, return of systemic logic and implementation of collaborative communication within current companies, etc.) necessarily implies the transition from a 2.1 university obeying the culture of fragmentation that separates services, people, knowledge and makes spontaneous use of digital technology to a 2.0 university that we qualify as "connecting".

\section{Connecting University 2.0}

Connecting University 2.0 is one that makes full use of social networks for collaborative educational purposes. Through the social web, trainers, students and managers collaborate, that is, act voluntarily to communicate (transmit, exchange or negotiate) within the framework of co-constructed projects governed by a global vision to which they all adhere. The university is "connecting" to the extent that it links what is untied by creating articulations at all internal and external levels, and this at the service of the development of collective skills and more generally of the collaborative communication that organizations would need. The methodological framework which could ensure the establishment and management of University 2.0 for collective operation targets specific objectives are listed below. 


\section{Goals}

Six in number, the expected results concern the effective professionalization of the dynamics of university training through the promotion of the collective skills that organizations require today. This implies the revision of educational engineering and training. Here is the inventory.

- Promote the professional integration of students

- Strengthen intra and inter university links

- Strengthen links between universities and businesses

- Further professionalize current training systems

- Promote collective skills at the service of enterprise 2.0

- To equip the trainer and the trainee in terms of technical and behavioural skills.

Underlying these objectives, the methodological framework designed is based on four guiding principles which give it durability and consistency. There are four principles that summarize the overall vision of our work; a vision with a systemic, interactionist, action-oriented vocation combining NICT and ethics.

\section{Guiding principles}

"Reliance": Whether scientific or human, "reliance" has a double meaning, it refers to the act of connecting or linking up and is, moreover, the result of this act [40]. In our case, it is a multidimensional articulation: articulation of individual skills, articulation of knowledge, articulation of uses, articulation of the academic and the entrepreneurial, and ultimately articulation of human communities in a collaborative perspective.

Primacy of the relational: Referring to the axiomatic model of Palo Alto, in particular to the axiom which argues that all communication has two aspects: content and relationship, such that the second includes the first and is therefore a metacommunication [41], we believe that the relationship should govern this educational project. Indeed, the relationship (which involves mutualisation and negotiation) should occupy the first rank in relation to technical content.

ICT and ethics: New Information and Communication Technologies, especially social networking, cannot be successful unless there is an axiological system that controls its use. The values of transparency, clear circulation of information, separation between behaviours and people who have demonstrated these behaviours, among others, are sine qua non conditions for an effective and lasting interaction between the available individual skills.

Transition from "in vitro" to "in situ": The methodological framework that we have designed is based, in its essence, on professionalizing situations and activities. In other words, it involves resorting to real or similar problems. The objective is to prepare students for this new version of enterprise 2.0.

In terms of project stakeholders, there are four stakeholders grouped into two categories, in these case internal and external ones. Internal stakeholders are students and trainers who are called upon to collaborate at different levels. As for external contributors, they are represented by field workers and business professionals. Communica- 
tion between the two internal and external stakeholders is ensured by an implementation committee. It is a multi-category team made up of heads of departments, the educational director and the various heads of courses of study. This logic is configured by the following diagram.

\section{$4 \quad$ University 2.0 Modeling}

\subsection{Main actors}

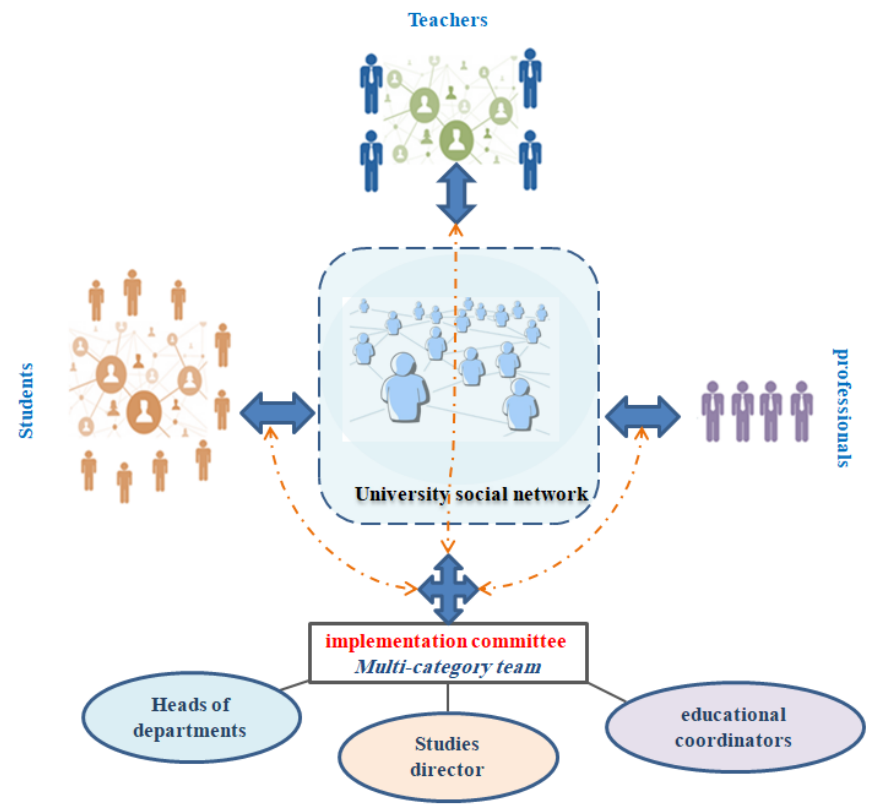

Fig. 2. Main actors in the university social network

\subsection{Installation conditions}

In order to successfully complete the project, a number of conditions seem important to us; sine qua non conditions that we have gathered in four synthetic points:

\section{a) Educational conditions}

- Training of trainers around the following axes: collective skills, social web, soft skills

- Sensitization of students to the importance of soft skills in their professional integration

- Development of a pooling and transparency charter

- Identification of the typical profiles expected by companies and development of a collective skills repository (Priority skills, collective skills, their connection, etc.) 
- Design of a framework of professionalizing situations (simulated and authentic)

- Design of a generic model for collective skills assessment grids

\section{b) Technical conditions}

- Configuration of a professional social network

- Creation of accounts for professionals

- Establishment of partnership agreements with companies with the same vocation and who are invited to propose problems on the ground

- Creation of a strategic watch office responsible for updating data according to techno-educational progress.

Taking into account this framing and in consideration of the parameters conditioning it, it would be advisable, now, to present the broad outlines of the methodological framework which we worked out in order to set up and develop collective competences within the university 2.0 , and in line with the requirements of the current company with collective and digital operation. Four phases organize the framework in question, namely the initiation phase, the partial immersion phase, the total immersion phase and the autonomy phase.

\subsection{Methodological framework for implementing university 2.0}

\section{Phase 1: Initiation (Preparatory years)}

- Development of the targeted behavioural skills: team spirit, initiative, creativity, listening skills, availability, sense of responsibility, negotiation

- Consolidation of the student's linguistic profile

- Cultural and intercultural issues

- Basic writing techniques: emails, minutes and reports

\section{Phase 2: Partial immersion}

Level 1:

- Development of individual skills (CI);

- Intra-modular projects (micro-projects for knowledge integration)

- Tools to use: social network and project management platform

Level 2 :

- Proposal of joint inter-modular projects

- Negotiation of content between trainers

- Compulsory use of the social network configured for the mobilization of collective skills (CC)

The following figure highlights the systemic logic to which university education should obey. In a tangible way, it shows the two moments which structure the socalled partial immersion phase. First, we look at the development of individual skills by means of micro-projects integrating the knowledge of each module separately and 
using the social network as well as the project management platform. In a second step, we seek to develop collective skills from complex projects articulating the contents of the different modules and involving the imperative use of the social network configured for this purpose.

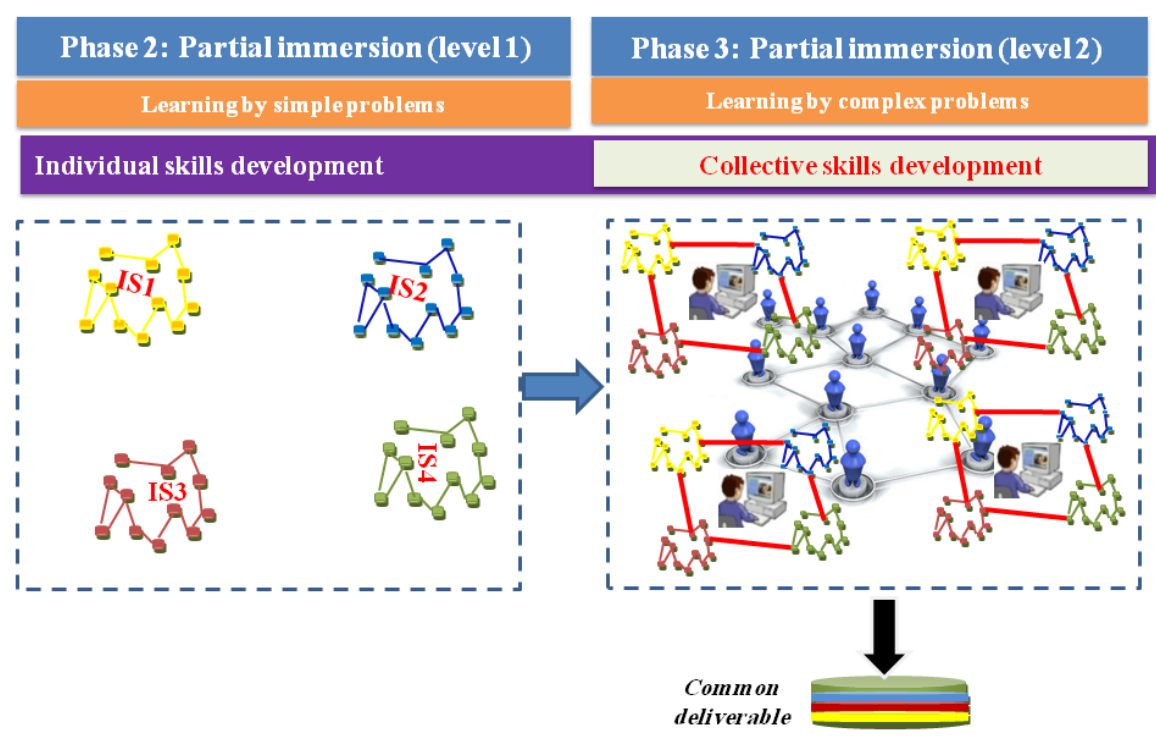

Fig. 3. Partial immersion: from individual competence to collective competence

\section{Phase 3: Total immersion (In vivo training practices)}

- Constitution of a bank of professionalizing situations: real subjects proposed by partner companies in the form of issues

- Development of individual digital portfolios

- Concerted choice of the problems communicated, and this according to the motivations of the students (common interest to be promoted)

- Implementation of specifications by a team of educational and professional supervisors (business representatives)

- Project planning: expected deliverables, training, timing, equipment, etc.

- Implementation and monitoring

- Evaluation and extensions

- Creation of a collective portfolio.

The synoptic representation below embodies well the functioning of in situ training characteristic of this phase of total immersion provided by a multi-category team. 


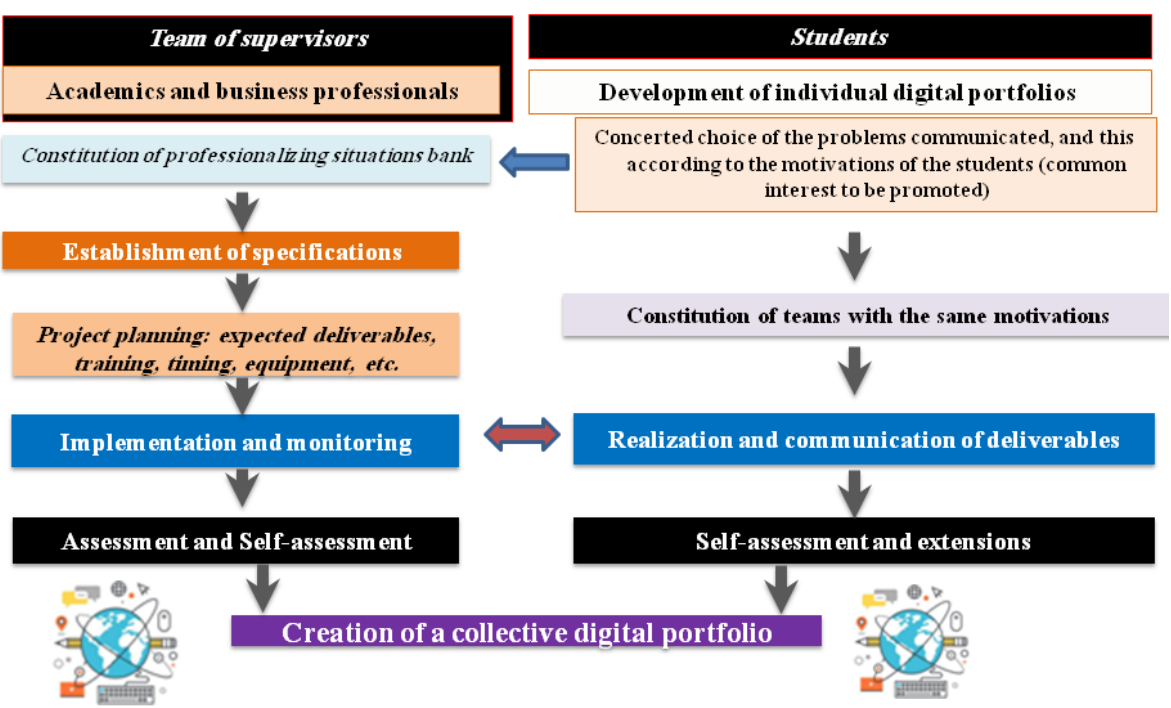

Fig. 4. Competence total immersion phase

\section{Phase 4: Autonomy (Creation and management of a virtual business)}

- Objectives

- Exercise collective and behavioural skills independently

- Manage behaviours in varied and unusual contexts

- Prepare for the co-action of enterprise 2.0

- Marketing the created company.

- Development in contractual terms of a code of conduct to be followed (soft skills)

- Setting up a joint project with tailor-made specifications:

- Formulation of objectives (according to the PORE and SMART methods)

- Establishment of a common repository

- Archiving and construction of a collective memory containing reports, results, processes

- Programming of training acclimatized to possible needs

- Negotiated proposal of a problem and treatment by the use of capitalized skills

- Development of a pre, inter and post project evaluation system

- Reflexive analysis engaging the young actors of the project

- Outlook: Launch of a 2.0 start-up.

This figure summarizes the components of the fifth phase by reviewing the targeted objectives and the actions to be undertaken in order to achieve them. 

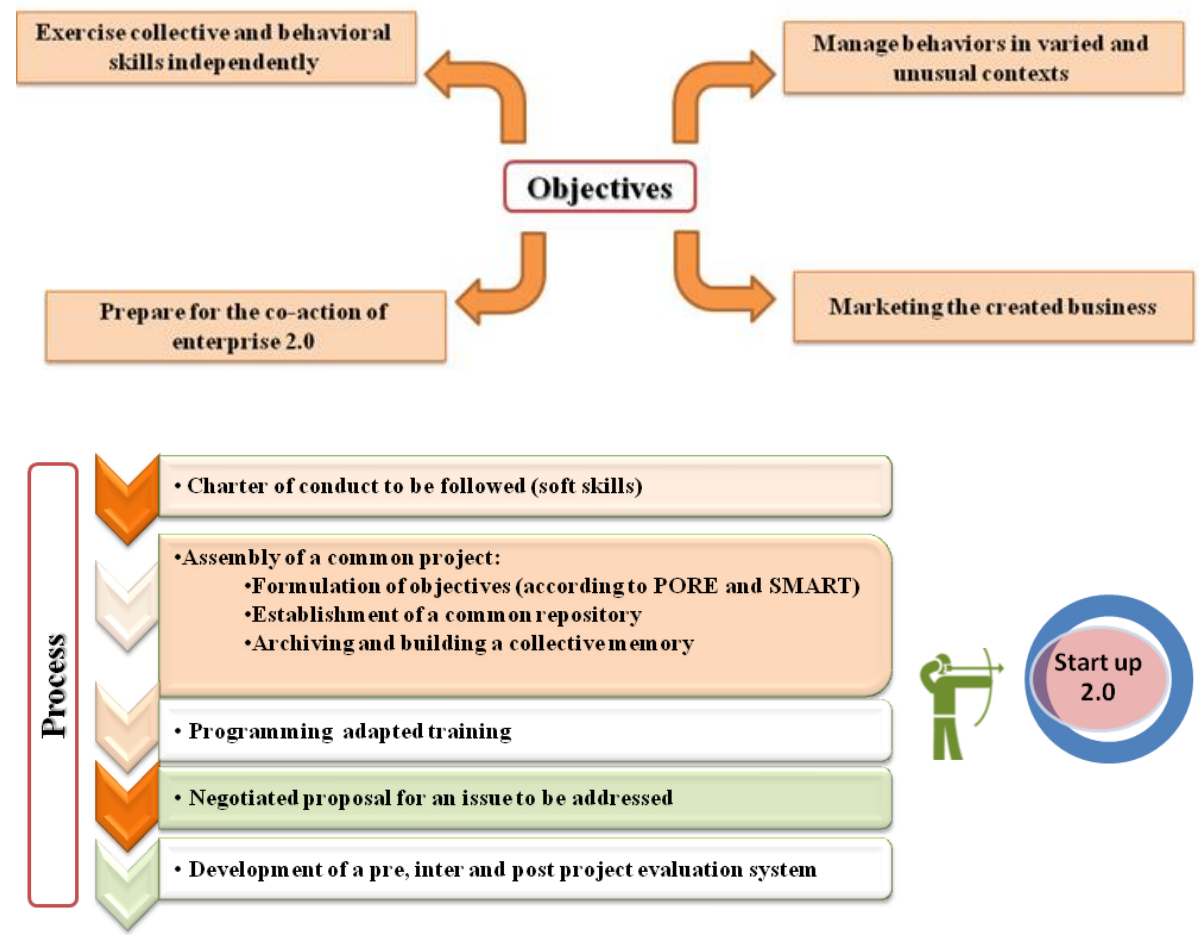

Fig. 5. Creation and management phase of a start-up.

Thus, we go from initiation to partial immersion then to total immersion to arrive at the phase of autonomy. Endowed with individual and collective, technical and behavioural skills thanks to a university environment governed by the complex and effectively dialoguing with the company, students are called upon to collaborate to design, manage and evaluate projects, the expected deliverable being the creation of a Startup 2.0, a real space to learn collaborative communication and take advantage of it even before entering the job market.

\section{Technical Architecture of the Proposed Model}

Our technical architecture is based on Multi-Agent Systems, ontologies [41] and learning machine algorithms. The use of an SMA, highly recommended in the case where the problem is very complex, heterogeneous but decomposable, makes it possible to have a certain robustness and to reduce the processing time of the programs 
using parallelism. The agents communicate with each other through ontologies sharing a common language.

By definition, a software agent is a system that interacts with its environment [42]. It is a program that accomplishes tasks independently, where other agents exist, to deliver the requested results. In addition, an agent is an entity that has skills enabling it to achieve its objectives based on the communications acquired. It is particularly endowed with the ability to interact with other agents: artificial or human (platform users). This dialogue is established using a common language, which implies the use of semantic web ontologies [43] which are used to define a common, unified and shared dictionary in order to ensure cooperation and communication between agents.

The main exchanges between agents include the definition of connections and the mechanisms of interactions between them [44]. In addition, the study of these interactions gives rise to the emergence of the "Multi-agent System" (SMA) paradigm. This is defined as a model developed to understand and analyse the dynamic interactions between agents within their environment. The latter include any action carried out within the ADM which is likely to generate a change in the behaviour of the other agent, with the aim of consolidating the capacities and knowledge of the agents involved to achieve their common overall objective.

\subsection{Layered modelling of the proposed system}

In order to design our system, we adopted a multilayer representation. The system is broken down into three main layers, each of which is made up of a set of specific agents that interact with each other. This representation makes it possible to have a high level of modularity and of decomposition of functionalities ensured by the agents.

Human-Machine Interface (HMI) layer: This is the layer that ensures communication between our university social network with its environment, especially its users. This layer provides the interfaces necessary for authentication and management of user accounts on the system. The software agents of this layer take care of managing and capturing the requests and the actions submitted by the users.

Main layer: This is the layer that represents the heart of our university social network. It is responsible for executing the functionalities related to the development of collective and individual skills as well as their assessments and which correspond to the following aspects:

- Management of student profiles

- Publication of professionalizing situations by professionals and academics

- Selection of suitable situations

- Development of specifications for each professional situation

- Planning and execution of the planning of the achievements of professional situations

- Prediction of homogeneity and success of naturally heterogeneous student groups

Establishment of horizontal collaboration between professionals and academics to carry out the sponsorship task etc.To ensure these functionalities, the intelligent software agents of this layer use methods stemming from artificial intelligence, in particu- 
lar the method of $\mathrm{K}$ plus neighbouring pockets for the elaboration of the profiles of the students and those of the supervisors. In addition, Bayesian networks are used to predict homogeneity and the success of naturally heterogeneous groups of actors (team of students and that of supervisors), for successful management of the achievement / supervision of professional situations.

Semantic layer: This layer illustrates the semantic modelling framework of the knowledge base necessary for reliable and rapid communication between the intelligent agents of our university social network. The channel for this communication is provided using the set of ontologies we have designed which represent a unified dictionary shared between the different software agents.

\subsection{Identification of the different agents and their roles in our SUSN}

We have designed all of the agents presented below in order to ensure an almost exhaustive execution of all the functionalities necessary for the development of Soft Skills, in particular collective skills. The following figure represents the set of designed agents distributed according to the layers of our System.

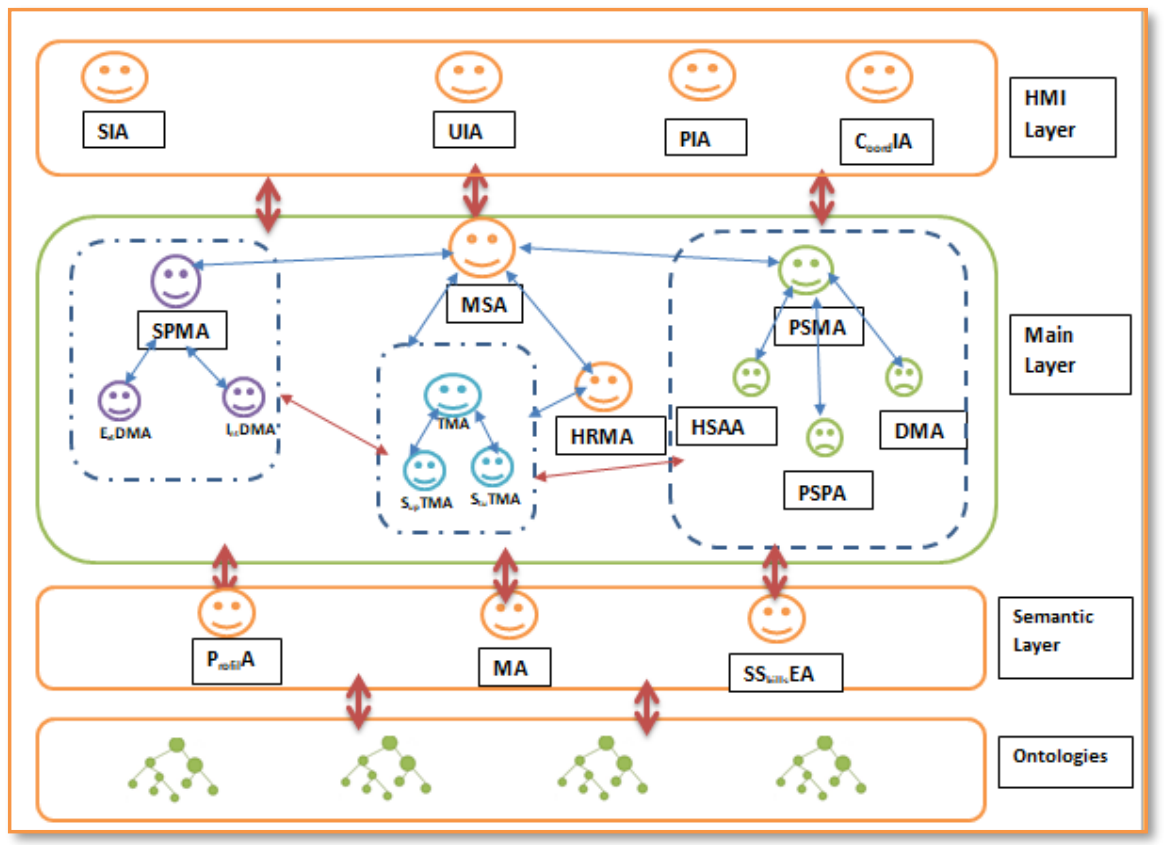

Fig. 6. Technical architecture of our Smart Social Network using MAS and ontologies. 


\section{Roles of HMI layer agents}

Student Interface Agent (SIA): this agent's role is to manage the access of students to the platform, to receive their requests and to transmit them to the system, it allows the student to:

- Authenticate

- Manage their account

- Consult the assessment of their skills

- Develop their skills by working as a team on professional situations

- Visualize the evolution of their skills etc.

University Interface Agent (UIA): this agent is responsible for providing an interface for teachers to interact with the social network; they can through this agent perform the following functions:

- Authentication

- Managing their account

- The publication of professionalizing situations

- Drafting and validation of specifications

- The validation of the forecast schedules drawn up by its student groups

- Evaluating student deliverables and sending them comments for improvement

- Monitoring the evolution of the collective skills of the groups of students they supervise

Professional Interface Agent (PIA): This agent is responsible for providing an interface for professionals in order to interact with the social network, they can through this agent perform the following functions:

- Authentication

- Managing their account

- The proposition of real issues

- Collaboration with educational teams for the drafting and validation of specifications

- The validation of the forecast schedules drawn up by its student groups

- Evaluating student deliverables and sending them feedback for improvement

- Monitoring the evolution of the collective skills of all students through a dashboard

Coordinating Interface Agent (CIA): This agent is in charge of ensuring the educational follow-up of students in their field and of developing the link with professional collaborators in order to diversify the learning offers and take advantage of their experience in the field. The person responsible for communication with the external network can, through the interface provided by this agent, perform the following functions: 
- Authentication

- ensuring that the group of students trained are homogenous

- Prospecting new professional partners

- The selection of subjects proposed by professionals

- Participation in the adaptation of subjects according to the needs of the sector

- Validation of student choices

- The validation of the provisional planning

- Evaluation of student deliverables

\section{Roles of main layer agents}

Main Switching Agent (MSA): It is a Hub Agent through which pass all requests to and from users of the system. It ensures the communication of the data necessary for each agent in order to carry out his task. It makes it possible to route requests from users or agents to the right destination.

Professionalizing Situations Manager Agent (PSMA): As its name suggests, this agent manages professionalizing situations in terms of addition, consultation, and publication, among others. To this end, it interfaces with the following sub-agents:

- Deliverable managing agent (DMA): It is an agent which manages all the deliverables of a project as well as the feedback of supervisors with respect to each deliverable.

- Professional situations publication agent (PSPA): This is an agent responsible for the publication of professional situations and all the various information related to it.

- Hard skills assessment agent (HSAA): This is an agent which is charge of the assessment of individual skills while communicating with teaching teams.

Team management agent (TMA): This agent manages the training of teaching teams and groups of students. For this purpose, it interfaces with the following subagents:

- Supervisory team manager agent (S $\mathbf{u p}$ TMA): This is an agent which manages all teaching teams while respecting the teaching rules established by the coordinator of the course.

- Student team manager agent (StuTMA): Agent which manages student groups based on their profiles to form homogeneous groups. In addition, this agent runs a Bayesian network model to calculate the probability of success for a group. If the groups formed do not have a probability of success above a certain threshold, the coordinator must intervene.

Student profiles management agent (SPMA): This agent manages student profiles using internal and external data. For this purpose, it interfaces with the following sub-agents:

- Internal data management agent (IntDMA): It is an agent that manages the set of student data generated by the platform relating to the management of collective and 
individual skills as well as any information that can contribute to enrichment of the profile.

- External Data management agent ( $\left.\mathbf{E}_{\mathbf{x t}} \mathbf{D M A}\right)$ : This is an agent which will use big data techniques to exploit external data; data from other social networks or teaching platforms, to feed the profiles of students.

- Human resources management agent (HRMA): This is an agent which manages all human resources using the social network. The registrations and authentication of students, teachers and professionals are managed by this agent.

\section{Roles of semantic layer agents}

Profiler agent (ProfilA): This agent draws up and analyses the profiles of the students in order to have useful and necessary information for the good functioning of the other agents. These profiles constitute the knowledge base of our Smart University Social Network, which are characterized by the following parameters:

Level of each individual and collective skill; personal and professional interests; level of engagement; respect for the timing of execution of tasks; homogeneity indicator, etc.

Soft skills evaluating agent (SSkillsEA): This agent executes learning algorithms to analyze the reactions of the students during the realization of professionalizing situations and assesses collective skills based on the following elements: the commitment of members " a team, respect for specifications and planning, mastery of project jargon, as well as the degree of respect for each article of the contract drawn up by all the members of a group.

Monitoring Agent (MA): This agent monitors the evolution of student profiles through the realization of the professional situations assigned to them. It then develops dashboards based on evaluation criteria established by the teaching teams and the system. This agent uses the results of the Soft Skills evaluator (SSkillsEA).

All these agents use semantic web ontologies, namely, the Ontology of professionalizing Situations, ontology of profiles, Ontology of Teams, etc.

\section{Conclusion and Future Work}

Ultimately and as revealed by the state of the art operated, the current context and the profound changes it has induced (globalization, competitiveness and search for performance, among others) have led companies to rethink their mode and opt for an authentically systemic approach promoting collective skills. To this end, they have largely taken advantage of technological progress, in particular the social web. Many examples materializing the paradigmatic and terminological shift that underpinned this new orientation have been reported.

However, enterprise 2.0 and the collaborative communication that it seeks to develop have led to the discovery of material and human difficulties and limits, linked to the exercise of power, the conflict over territory and above all the fragility of values and behavioural skills. Hence the obvious usefulness of training and the preponderant role of the university which suffers, paradoxically, from multiple dysfunctions (com- 
partmentalization of knowledge, lack of intra and inter-modular articulation, loneliness of departments, absence of a real dialectic between the academic and the entrepreneurial, etc.).

The model that we have developed is very timely to transcend this problem situation, if only partially, and, as a result, fill a perceptible lack in the two environments concerned. It is a techno-educational model (SRSU) which aims to develop collective skills within universities. This formal system of professionalization of social networks is likely to strengthen not only individual skills (technical and behavioural) but also the collective skills required elsewhere. In order to implement it, we proceeded to the conception of a methodological framework which integrates concrete and easily concretizable methods.

Ensuring multiple alliances, internally and externally, enhance collaboration within the framework of global projects questioning all modules and engaging all departments and this in negotiation with companies, ensuring a clear and formal dialectic between them and businesses, promoting collective action and the structured and structuring use of digital technology, so many added-value and not the least targeted by this research work, setting, therefore, the milestones of a new approach to university practices; professionalizing approach, methodically backed by digital technology and transcending divisions in the service of enterprise 2.0 with a co-action tendency.

Many questions remain unanswered, however. Let us cite three that seem essential to us: How is the proposed system made a cutting-edge opportunity to ensure the professional integration of young graduates properly and effectively? How to motivate companies to engage with universities to guarantee mutual gain? Ultimately, how to assess collective skills to build a profile with three facets (Personal (selfassessment), educational (academic assessment) and Professional (business assessment)?) As for prospects, it seems that a field research for the design and testing of a collective digital portfolio would add value to this emerging project.

\section{$7 \quad$ References}

[1] Elda Tartari, Alban Tartari and Dilina Beshiri "The Involvement of Students in Social Network Sites Affects Their Learning",iJET vol.14 No 13, 2019. https://doi.org/10.3991/ ijet.v14i13.10453

[2] Masami Yoshida "An Investigation of the Social Network System Competencies of High School Students in Japan " iJET, Vol 13, No 5, 2018

[3] Storhaye, Patrick (2016), Transformation, RH et digital, De la promesse à la feuille de route, Paris, Editions EMS.

[4] Verrier, Gilles et Bourgeois, Nicolas (2016), Faut-il libérer l'entreprise? Confiance, responsabilité et autonomie au travail, Paris, Collection Stratégies et management, Dunod.

[5] Le Boterf, Guy (2004), Construire les compétences individuelles et collectives La compétence n'est plus ce qu'elle était, Troisième édition, Éditions d'Organisation. https://doi.org/ $10.4000 /$ books.pur. 10890

[6] DUBOIS Marc. et RETOUR Didier. (1999), « La compétence collective : validation empirique fondée sur les représentations opératoires de travail partagées » In, Psychologie du Travail et des Organisations, vol. 5, n 1-2, pp. 225-243. https://doi.org/10.3917/dunod.va $\underline{\text { lle.2016.01.0005 }}$ 
[7] Gullhon, Alice et Trepos, Georges (2000), « La compétence collective, le chaînon manquant entre la stratégie et la gestion des ressources humaines », Montpellier, Actes du Congrès de l'AIMS. https://doi.org/10.2307/j.ctv18phbc4.13

[8] Dupuich-Rabasse, Françoise et Trepos, Georges (2002), «Compétences collectives, NTIC et Knowledge Management: la place de la GRH dans la mise en œuvre des outils stratégiques de gestion l'entreprise », 13ème congrès de annuel de l'AGRH Nantes, tome 2, Actes, p. 9-21. https://doi.org/10.3917/geco.097.0039

[9] Defélix, Christian, Le Boulaire Martine, Monties, Vanessa et al., « La compétence collective dans le contexte de la globalisation du management : retrouver le lien avec la performance », @GRH, 2014/2 (n 11), p. 31-50. https://doi.org/10.3917/grh.142.0031.

[10] Lave, Jean (1988), «Cognition in practice: Mind, mathematics and culture in everyday life», APA Psyc Net (American Psychological Association) https://psycnet.apa.org/ record/1988-98562-000 https://doi.org/10.1017/cbo9780511609268.

[11] Kerbrat-Orecchioni, Catherine, (1990), Les interactions verbales, tome I, Paris, A. Colin

[12] Filliettaz,Laurent et Schubauer, Léoni (2008). Processus interactionnels et situations éducatives, Bruxelles, collection Raisons éducatives, De Boeck, p.10. https://doi.org/10.3917/ dbu.filli.2008.01

[13] Storhaye P. (2016), « Transformation RH \& digital », Editions EMS

[14] Verrier G. et Bourgeois N. (2016), « Faut-il libérer l'entreprise ? », Dunod

[15] Defelix C., Le Boulaire M., Monties V. et Picq T. (2014), « La compétence collective dans le contexte de la globalisation du management : retrouver le lien avec la performance » in «@GRH, Meilleurs papiers du 25è congrès de l'AGRH à Chester (6-7 novembre 2014) » De Boeck p. 31-50. https://doi.org/10.3917/grh.142.0031

[16] Dufresne D., Peyrat-Guillard D. (2009), Communication au congrès de l'AGRH de Toulouse le 21/09/2009, p. 20

[17] Plane J.M. (2015), « Théories du leadership », Dunod

[18] Ollivier D. (2012), « Management 2.0, Performance économique et capital humain », Afnor éditions

[19] Le Boterf (2000), « Construire les compétences individuelles et collectives », Les Editions d'organisation

[20] Le Boterf (2015), « Construire les compétences individuelles et collectives », 7ème édition argumentée, Eyrolles

[21] Bataille F. (2001), « Compétence collective et performance », Revue de Gestion des Ressources humaines, avril-mai-juin, p. 66-81

[22] Dupuich-Rabasse F., Trepo G. (2002), « Compétences collectives, NTIC et Knowledge Management : la place de la GRH dans la mise en œuvre des outils stratégiques de gestion de l'entreprise», Actes du 13ème congrès de l'AGRH, tome 2. https:// doi.org/10.3917/mav.009.0083

[23] Retour D. et Krohmer C. (2006), « La compétence collective, maillon clé de la gestion des compétences », in Defelix C., Klarsfeld A. et Oiry E. (coord.), « Nouveaux regards sur la gestion des compétences », Vuibert, p. 149-183. https://doi.org/10. 3917/jgem.116.0305

[24] Loufrani-Fedida, Sabrina; Angué, Katia (2009), Pour une approche transversale et globale des compétences dans les organisations par projets. Gestion des compétences : nouvelles relations, nouvelles dimensions, Vuibert, pp.123-148. https://doi.org/10.3917/mav.058.00 $\underline{14}$

[25] Michaux V. (2009), «Articuler les compétences individuelle, collective organisationnelle et stratégique : les éclairages de la théorie des ressources et du capital social » in Defelix 
C., Picq T. et Retour D. (coord.), « Gestion des compétences, Nouvelles relations nouvelles dimensions », Vuibert, p. 13-33. https://doi.org/10.3917/grh.132.0041

[26] Le BOulaire M., Retour D. (2008), Gestion des compétences, stratégie et performance de l'entreprise : quel est le rôle de la fonction RH ?, Revue de Gestion des Ressources Humaines, 70, 51-68. https://doi.org/10.2307/j.ctv18phbc4.5

[27] Grimand, A. (2009). Des compétences individuelles aux compétences stratégiques : un essai de modélisation des stratégies concurrentielles fondées sur les ressources humaines. In Retour, D., Picq, T., et Defelix, C. (Eds.), Gestion des compétences : nouvelles relations, nouvelles dimensions. Paris, Vuibert, pp. 35-57.

[28] Rouby Évelyne, Thomas Catherine (2014), « La construction de compétences collectives en environnement complexe : une analyse en termes d'attention organisationnelle. Le cas exploratoire de la conduite d'un four de cimenterie », @GRH, 2014/3 (n 12) https://www. cairn.info/revue-@grh https://doi.org/10.3917/grh.012.0039

[29] Falzon, 1991, «Les activités verbales dans le travail », Modèles en analyse du travail

[30] Le Boterf, Guy (1994), De la Compétence. Essai sur un attracteur étrange, Paris, Eyrolles.

[31] Girod-Seville, M. (1995), La mémoire organisationnelle, Revue française de gestion, $n$ 105, septembre-octobre, p. 30-42

[32] Wittorski, R. (1997). Analyse du travail et production de compétences collectives. Paris : L'Harmattan.

[33] Pemartin, D. (1999). Gérer par les compétences ou comment réussir autrement ? Paris : Editions Management Société. https://doi.org/10.7202/051321ar

[34] Picq T. et Retour D. (2001), « La coopération dans les organisations par projets. Les politiques de gestion des ressources humaines-, Personnel, (417), pp. 29-39. https://doi. org/10.4000/books.pum. 15541

[35] MichelleConlin and al., 2009, "Managing the Tweets", business week, 1er juin 2009, p.2021.

[36] Andreja Istenic Starcic, Margaret Barrow, Matej Zajc and Maja Lebenicnik “Students' Attitudes on Social Network Sites and their Actual Use for Career Management Competences and Professional Identity Development" iJET, Vol.12 No 5, 2017. https://doi.org/10.3991/ ijet.v12i05.6778

[37] Hoblingre Klein and al ,2017, « Utiliser LinkedIn en entreprise et hors-entreprise : entre stratégie collective et individuelle», Laboratoire interuniversitaire des sciences de l'éducation et de la communication, Université de Strasbourg, in ISTE OpenScience, $\mathrm{Pu}$ blished by ISTE Ltd. London, UK - openscience.fr . https://doi.org/10.21494/iste.op.2019. $\underline{0378}$

[38] Alexandre Largier and al., 2008, «Quelle prise en compte des compétences collectives et distribuées dans la gestion des compétences professionnelles ? », Perspectives interdisciplinaires sur le travail et la santé URL : http://journals.openedition.org/pistes https://doi. org/10.4000/pistes. 2167

[39] Bolle De Bal, Marcel, 2003« Reliance, déliance, liance : émergence de trois notions sociologiques»In Dans Sociétésn 80, p.99-131. https://doi.org/10.3917/soc.080.0099

[40] Watzlawick and al., 1979 « Une logique de la communication ». Paris, Le livre de poche, $280 \mathrm{p}$

[41] Jaber El Bouhdidi, Mohamed Ghailani, Abdelhadi Fennan "A Probabilistic Approach for the Generation of Learning Sessions Tailored to the Learning Styles of Learners", Vol 8, No 6, 2013. https://doi.org/10.3991/ijet.v8i6.3084

[42] Anne, Nicolle. 2002. Les Systèmes Multi-Agents.

[43] Gandon, F., 0. Faron, C. Zucker, and O. Corby. 2012. Le Web Sémantique: Comment Lier Les Données et Les Schémas Sur Le Web? Paris: Dunod. 
[44] Macal, C. M., and M. J. North. 2010. "Toward Teaching Agent-Based Simulation.” In Winter Simulation Conference, , 268-77

[45] Dr. Axel Zafoschnig "The Development of the new ING.PAED.IGIP Curriculum into an Umbrella for Modularised National and Regional Engineering Education Curricula", iJEP vol.4 N 1, 2014. https://doi.org/10.1109/icl.2013.6644575

[46] Veltz P. et Zarifian P. (1994), «Travail collectif et modèles d'organisation de la production», Le Travail Humain, 57 (3), 1994, pp.239- 249.

\section{Authors}

Hamid Bargach is a PhD holder in information and communication sciences from Abdelmalek Essaadi University (UAE, Morocco). Former trainer of teachers at the Regional Center for professions in Education and Training (CRMEF), specialized in the didactics of languages and cultures. Currently, he is a professor of communication at the King Fahd School of Translation (ESRFT) and an active member in the research laboratory of translation and information and intercultural communication sciences.hbargach@uae.ac.ma

Mohamed Ghailani is a PhD holder and Professor of Computer Science at the National School of Applied Sciences of Tangier in Morocco. He has led several trainings for the benefit of the teachers of the Ministry of National Education of Morocco: Competencies approach, planning of learning, ICT for Education, etc. Currently, he is a member of the research laboratory: LabTIC, ENSA of Tangier. His research interest includes Web Semantic, multi-agents systems, e-learning Adaptive Systems and Big datamining. He has several papers in international conferences and journals. mghailani@uae.ac.ma

Jaber El Bouhdidi is HDR at the University Abdelmalek Essaâdi - National School of Applied Sciences of Tetuan, Morocco. He is member of the SIGL Laboratory. His research interest includes Web Semantic, multi-agents' systems, e-learning Adaptive Systems and Big data mining. He has published several papers in international conferences and journals.

Article submitted 2020-09-24. Resubmitted 2020-11-10. Final acceptance 2020-11-11. Final version published as submitted by the authors. 